\title{
The role of environmental factors in modulating immune responses in early life
}

\section{Duncan M. MacGillivray and Tobias R. Kollmann*}

Division of Infectious and Immunological Diseases, Department of Paediatrics, Child and Family Research Institute, University of British Columbia, Vancouver, BC, Canada

\section{Edited by:}

Arnaud Marchant, Université Libre de Bruxelles, Belgium

Reviewed by:

Sampa Santra, Harvard Medical School, USA

Gregory B. Lesinski, The Ohio State University Comprehensive Cancer Center, USA

\section{*Correspondence:}

Tobias R. Kollmann, Division of Infectious and Immunological

Diseases, Department of Paediatrics, Child and Family Research Institute,

University of British Columbia, 938

West 28th Avenue, Vancouver, BC

V6H 3X8, Canada

e-mail: tkollm@mac.com
The concept of immunological memory stipulates that past exposures shape present immune function. These exposures include not only specific antigens impacting adaptive immune memory but also conserved pathogen or danger associated molecular patterns that mold innate immune responses for prolonged periods of time. It should thus not come as a surprise that there is a vast range of external or environmental factors that impact immunity. The importance of environmental factors modulating immunity is most readily recognized in early life, a period of rapidly changing environments. We here summarize available data on the role of environment shaping immune development and from it derive an overarching hypothesis relating the underlying molecular mechanisms and evolutionary principles involved.

Keywords: evolution, environment, innate immunity, immunologic memory, immune system, pediatrics, ontogeny

\section{INTRODUCTION}

The immune system is an organ that specializes in responding to environmental exposures. Its tasks are to determine friend from foe, innocuous from dangerous, inert from toxic. This highly complex task is most readily recognized during rapid changes of environmental exposures such as those occurring in early life. The purpose of this review is to amalgamate existing data into a cohesive vision on how early life environmental exposures leave a lasting impression on the human immune system, and how this impression can either have beneficial or potentially deleterious effects. This vision incorporates the key principles of the developmental origin of health and diseases $(\mathrm{DOHaD})$ hypothesis, the hygiene hypothesis as well insights from the field of developmental immunotoxicology (DIT) and posits that the sum of these mold immune memory. Immune education includes not only the classical acquired adaptive immune system with the cardinal feature of long-term immune memory but also the more recently described trained memory of the innate immune system. Understanding the environmental engines that drive development of the immune system is not only necessary to address specific pediatric diseases but also to identify the strategies to change trajectories toward long-term, life-long protection from disease.

\section{ONTOGENY OF THE IMMUNE SYSTEM}

Ontogeny refers to the study of development. As multicellular life evolved so too did cell types with discrete functions. The immune system has evolved to meet a fundamental challenge of multicellular life determining whether exposures are benign or harmful. The seeding and growth of mammalian organs are a highly regulated sequence of events. Periods of rapid development represent windows of vulnerability for dysregulation with subsequent downstream effects that may manifest much later in adult life. Our interest in the immune system is focused upon how it comes to be fully functional, and to try to elucidate how and when aberration can result in disease, and how to best prevent undesirable outcomes. Thus, it is necessary to first understand the earliest origins of immune cells.

Cells making up adaptive and innate arms of the immune system are derived from lymphoid or myeloid progenitors. Hematopoietic stem cells (HSCs) are the canonical precursors of all immune cell lineages and are defined by their capability to replace all blood lineages in lacking recipients (1). HSCs migrate from the yolk sac and aorta-gonad-mesonephros region into the fetal liver, to ultimately reside in the bone marrow in adults where they constantly self-renew and differentiate to replace the rapid turn over of circulating immune cells. In addition, there are multipotential progenitors that can give rise to myeloid and lymphoid cells independent of the yolk sac (2-4). These cells may arise from within the embryo or from extra embryonic sites such as the placenta and vitelline arteries (5). Cell types such as tissue resident macrophages may be derived from monocytes of bone marrow origins or from self-potentiating cells of embryonic yolk sac origin (6). It is yet unknown whether cells with similar roles and phenotypes derived from independent origins have identical functions, programing, and responses to immunological challenges.

Age dependent differences in human immunity are implied by the clinical observation of altered disease susceptibility and substantiated by differences in immune cell activities. Newborns are more susceptible to several diseases when compared to adults; this appears to be at least partially due to a lack of acquired immune memory and differential regulation of innate immune responses $(7,8)$. This altered immunological priming is not maladaptive, 
rather, the fetus and neonate are challenged with balancing defense against infection, minimizing potentially harmful inflammation, and mitigating colonization by microbes as it develops and transitions from the relatively protected womb to the external world (9). Over the first few years of life the capacity for the immune system to exert a balanced and rapid response becomes increasingly salient. Though human neonates are capable of mounting adaptive T-cell responses, CD4 T-cell responses are slower to develop and have a predisposition to T helper- 2 (Th2) or Th17 responses against extracellular pathogens (10). In contrast, Th1 responses are important for defense against intracellular pathogens and cell mediated immunity, and reach adult levels only after about 2 years of age (10).

The abridged Th1 response is manifest in reduced defense against intracellular pathogens and is influenced in part by different innate cell cytokine responses to pathogen associated molecular patterns (PRRs) that direct subsequent adaptive immune functions (11). These are receptors associated with the innate immune system that recognize conserved regions on broad phyla of organisms and through signaling cascades guide subsequent immune responses. Neonatal innate immune cells including monocytes, plasmacytoid dendritic cells, and conventional dendritic cells produce less interleukin (IL)-12p70 and type I interferon and similar or higher levels of IL-1Beta, IL-6, IL-23, and IL-10 than adult cells when stimulated by the same PRRs (8). In addition to compromised cytokine response, neonatal cells have also been shown to exhibit relatively limited ability to produce multiple cytokines in polyfunctional responses to PRR stimulation. Perinatal anti-inflammatory cytokine production of IL-10 decreases in concert with increasing pro-inflammatory responses (such as tumor necrosis factor alpha and IL-1Beta) over the first few years of life while neonatal antiviral cytokine (type 1) responses already reach adult levels after the first month of life (12). Underlying patterns of immune ontogeny lead to windows of vulnerability to different types of infection during different stages of development (13). While age dependent development of the immune response may also follow genetically encoded programs, increasing evidence from several fields suggest that these changes in immunity are profoundly impacted by external environmental influences. Exemplified by successfully acquired specific and non-specific responses to vaccination, programing early in life represents not only a window of vulnerability but also a window of opportunity for long-term prevention of infectious diseases and maintenance of homeostasis and health.

\section{DOHAD AND EARLY LIFE PROGRAMING}

The developmental origins of health and disease (DOHaD) hypothesis have been gradually increasing in popularity since the 1980s. Conceptually, DOHaD posits that presentation of adulthood disease can be traced back to childhood, perinatal, or in utero exposures. Observations that nutritional status during gestation can influence organogenesis and metabolism in later adulthood lead Dr. David Barker to pursue and expand the ideas of $\mathrm{DOHaD}$ (14). The current paradigm states that fetal adaptations to intrauterine and maternal conditions during development shape structure and function of organs $(14,15)$. Alternate development and programing are not maladaptations per se, but represent transient responses to environmental demands that confer shortterm survival, potentially establishing lasting implications for later health. The immune system represents the prime example of the $\mathrm{DOHaD}$ concept, as the immune status is precisely defined by the amalgamation of interactions with the environmental exposures of a given individual. The immune system is the $\mathrm{DOHaD}$ organ par excellence and even contains mechanistic parallels in that early life programing directs later immune health through epigenetic modifications, the modus operandi of $\mathrm{DOHaD}$.

Epigenetic modifications are defined as mitotically or meiotically heritable changes in accessibility of genes for expression that do not involve a change in DNA sequence (16). There are numerous types of epigenetic modifications including DNA methylation, histone modification, nucleosome position, and non-coding RNA expression (17). These modifications alter gene expression and explain how identical DNA can result in entirely different phenotypes and cell lineages. In humans, environmental exposures can drive epigenetic modification that allow for innate immune cell programing as demonstrated by examples from trained immunity (18). Epigenetic programing is also an important factor in adaptive immune T-cell activation (19) and memory response (20). Cell ontogeny is dependent on epigenetics, and development represents a time where immune priming may be taking place with lasting implications for subsequent health and disease.

\section{DEVELOPMENTAL IMMUNOTOXICOLOGY}

Numerous environmental factors can influence immune activity, and the field of developmental immunotoxicology (DIT) has arisen to assess how chemical, biological, physical, or physiological factors alter the development of the immune system. Immunotoxic substances have traditionally been identified based on observation of pathology in adults, and may miss potential harm during development. Only now are we beginning to investigate how some exposures may affect pediatric populations and human development (21). Following selective examples of naturally occurring and synthetic compounds illustrate how immunotoxic exposures can influence the immune system.

Depending on concentration naturally occurring heavy metals (e.g., $\mathrm{Cd}, \mathrm{Hg}, \mathrm{Pb}$ ) can be either immunopotentiating or immunosuppressive (22). Heavy metals are capable of crossing the placenta; the effects of which depend on the dose, length, and timing of exposure $(23,24)$. Cadmium exposure demonstrates dose-dependent suppression of circulating IgG in children and is associated with adult diabetes and impaired fasting glucose $(25,26)$. In utero exposure to methylmercury can decrease T-cell functionality, alter circulating immunoglobulin levels and has been implicated with low birth weight and preterm birth (2729). Neonatal immunotoxicity can occur well below adult safety thresholds (30). Arsenic exposure may lead to direct effects on immunity through epigenetic programing involving leukocytes and metabolic physiology (31-36).

The immune system now encounters synthetic compounds absent from our evolutionary history. We know relatively little about the lifelong effects of synthetic compounds and they have only recently been studied for early life exposures. Three major classes of synthetic compounds include tetrachlorodibenzo-o-dioxins (TCDDs), perfluorinate 
compounds (PFCs), and polychlorinated biphenyls (PCBs); all of which are capable of crossing the placenta and the latter two have been detected in breast milk (37-40). Effects on immune function are compound dependent. TCDDs have been associated with hypothyroidism, inhibition of thymocyte maturation, reduced MHC II expression, altered T-cell differentiation, and decreased blood thyroid stimulating hormone $(39,41,42)$. PFCs are known to suppress innate immune cytokine responses (43) and appear to lower antibody response to some childhood immunizations (44). PCB exposure has been linked to neonatal thymus size (45), alteration of childhood adaptive immune cell populations, impaired vaccine responses (46), and increases in childhood middle ear infections $(47,48)$. Synthetic compounds may have long-term effects due to bioaccumulation in tissues with high fat content or relatively long half-lives (averaging around 10 years for PCBs) and slow clearance $(37,49)$.

Risk of exposure to immunotoxic substances can be mediated by cultural predilections, including diet, alcohol consumption, and smoking of cigarettes. Alcohol use during pregnancy can result in fetal alcohol spectrum disorders (FASD), extensively reviewed elsewhere (50). Briefly, children with FASD have modulated innate and adaptive immunity (51), and maternal alcohol abuse has been associated with infection risk in newborns $(51,52)$; long-term effects may be potentiated through epigenetic modifications (5355). Early life exposure to cigarette smoke has been linked to increased respiratory and ear infections $(56,57)$, altered innate cytokine production (58), and changes in adaptive cell populations (59). Removing or mitigating cultural sources of immunotoxic compound exposure may indeed be attainable but will require multidisciplinary efforts and community engagement.

The field of DIT is demanding increased immune-surveillance in developing subjects and shows promise for explaining some underlying risk of infectious and non-communicable global disease burden. There is limited and incomplete knowledge about the developmental immunotoxicology of many compounds (both synthetic and natural) but there is compelling evidence that these substances can subtly and dramatically alter human immune systems. It has been suggested that even relatively mild or seemingly benign alteration of immune response may set the stage for disease (60). Factors such as lead, methylmercury, TCDD, and tobacco smoke are considered causal for modifying sub-clinical immune dysfunction that compounded with infection can trigger disease states (61). Immunotoxicological effects can take place in the womb, and more thorough understanding of the maternal environment is required to further explore immune programing at this stage.

\section{MATERNAL ENVIRONMENT}

Pregnancy impacts both neonatal and maternal immune status. Half of neonatal genetic material is paternally derived and can be targeted by maternal immune responses as non-self, resulting in targeted rejection of the developing neonate. Extensive research has revealed that interaction between maternal and fetal tissues is mitigated by local immune evasion as well as maternal immune modulation, though exactly how is not yet fully understood (62). For instance, the syncytiotrophoblasts that make up the majority of the maternal-fetal interface express alternate forms of major histocompatibility complexes (MHC) that may help enable fetal evasion of maternal immune response (63-65). These cells, and the maternal uterine mucosa, produce indoleamine 2,3 dioxygenase in response to interferon-gamma that suppresses adaptive T-cell proliferation (66). Potential adaptive responses may be further abrogated during pregnancy by an expansion of T-regulatory cell subsets. In murine models, T-regulatory cell expansion has been associated with increased susceptibility to some infections. Susceptibility to pathogens was reduced with removal of T-regulatory cell populations; however, this also triggered maternal immune activity and fetal resorption (67). Pregnancy also changes levels of circulating hormones such as estradiol, progesterone, and estriol that have pleiotropic effects on both adaptive and innate immune cells (68). Immune modulatory effects of pregnancy associated hormones may partially explain observed decreases in severity of maternal inflammatory disease, such as rheumatoid arthritis $(69,70)$, and increased susceptibility to some infections $(71,72)$. Maternal immune activity is altered during pregnancy both in the womb and systemically. Altered maternal immune status during the perinatal period meets the demands of pregnancy but also can have implications for infectious diseases.

\section{DISEASE SUSCEPTIBILITY AND SEVERITY ASSOCIATED WITH PREGNANCY}

There is clinical evidence for maternal immune modulation given that pregnant women have different susceptibility and severity to certain infectious diseases when compared to the general population (71). While pregnant, women are more susceptible to malaria, listeriosis, and human immunodeficiency virus (HIV) type 1 infection (72). Evidence from malaria research suggests that altered susceptibility to disease from certain pathogens is likely due to the appearance of newly derived fetal tissues, such as the placenta. In malaria endemic regions with high rates of transmission, women are generally asymptomatic, however, during pregnancy even previously asymptomatic women may present with disease. Acute disease state appears to be related to variable surface antigens generated by the parasite that results in sequestration of infected erythrocyte at the placenta (73). Accumulation of infected erythrocytes results in local inflammation associated with pathogenesis and adverse pregnancy outcomes (74). During pregnancy, women also suffer more severe infections from influenza, hepatitis $\mathrm{E}$ virus (HEV), herpes simplex virus (HSV) (72), and with more limited evidence to measles, smallpox, and varicella (71). Decreased proportions of circulating maternal T, B, and NK cells may represent weakened responses against intracellular pathogens that explain increased disease severity to some infections (75).

Maternal infection status has implications for fetal immune development. Diverse pathogens are capable of infecting the developing fetus either via maternal circulation and the placenta or through the uterine tract (76). Chorioamnionitis can lead to preterm birth and associated morbidity and mortality (77). Beyond direct transmission or infection of the neonate, in utero exposure to inflammation, soluble factors, and antigen can alter neonatal immune status (78). Maternal infection can have lasting implications for the neonatal immunity both for subsequent infection with the same agents, or in more general immunomodulatory ways that changes risk of other infections (79). 


\section{MATERNAL INFECTION IMPACTS NEONATE IMMUNE PROGRAMING}

Maternal infection during gestation has implications for neonatal immunology. Effects can be specific to the infectious agent or general modulation of the host immune system. Infection with helminths such as Wuchereria bancrofti (80-82) and Ascaris lumbricoides $(83,84)$ results in increased risk of post-partum infection in early life. Active helminth infection also has non-specific general effects on host immunity that enable continued parasitic evasion of host defenses. Human helminth infections are associated with skewing of the host immune response to a Th2 predisposition (85), chronic immune activation, hyporesponsiveness, and immune anergy (86). This immune modulation can impair response to and efficacy of some vaccines (87-90). During pregnancy these off target effects can increase mother-to-child transmission of HIV (91) and alters transplacental transfer of circulating antigen specific antibody to other infectious agents, such as TB that could interfere with vaccination (92). Thus, exposure to helminths in utero can result in specific and non-specific immune programing changing the risk of perinatal infections and vaccine responses.

\section{IN UTERO EXPOSURE TO HIV MODULATES OFFSPRING IMMUNITY}

Maternal infection can also directly expose the fetus to pathogen that may cross the placenta, be transmitted during birth, or by contact early in life. HIV is a well characterized infectious disease with profound impacts on the immune system. The use of antiretroviral drug regimes can increase quantity and quality of life for infected individuals, and perinatal treatment can block the majority of mother to child transmission of the virus. However, HIVexposed uninfected (HEU) children have increased morbidity and morality compared to unexposed children $(93,94)$. HEU children have been shown to display altered innate cytokine responses early in life $(95,96)$, impaired T-cell proliferation, reduced cytokine polyfunctionality, and have reported higher and lower responses to vaccination $(97,98)$.

Altered neonatal immune status may be due to transplacental transmission of soluble immune factors, exposure to viral antigen, or reduction of breastfeeding by HIV+ mothers. Maternal burden of infection may have significant implications for neonatal immune ontogeny; high maternal viremia has been associated with significantly lower CD4+ T-cell count in uninfected progeny (99). Transmission of viral antigens may also be influencing neonatal immune development as a third of HEU children appear to have detectable virus specific responses (100). Breastfeeding can result in vertical transmission of HIV and interfere with vaccine responses; however, avoidance or early cessation of breastfeeding has been shown to be detrimental for infant health outcomes (94, 101-103). The World Health Organization currently recommends for breast feeding as benefits appear to outweigh risks of vertical HIV transmission (104). The lifelong implications of in utero exposure to HIV are not currently known but will gradually unfold as this population increases in size and maturity.

\section{BREAST FEEDING}

Breast feeding provides not only necessary caloric and nutritional provisions for the growing neonate but also important factors for immune development. Human milk contains proteins that aid digestion, have antimicrobial activities, and act as sources of amino acids for the developing neonate. Bile salt-stimulated lipase aid lipid digestion, alpha amylase may promote complex carbohydrate metabolism, beta casein increases the bioavailability of divalent cations such as calcium and zinc, and lactoferrin facilitates uptake of iron, stimulates gut cytokine production and release, and may have antimicrobial effects (105). These and other factors suggest that colostrum and breast milk are important for neonatal immune ontogeny. Human milk contains numerous immune modulatory proteins such as immunoglobulins, lysozyme that degrades gram positive bacterial outer cell walls, and kappa-casein that blocks pathogen binding to the gastric mucosa (105). Soluble and cell secreted cytokines including IL-1Beta, IL-6, IL-8, IL-10, tumor necrosis factor alpha, granulocyte- and macrophagecolony stimulating factor (GM-CSF) are present in human breast milk (106). The first meal of a breastfeeding neonate is generally colostrum that contains more immune factors that regular breast milk, including maternal immune cells such as neutrophiles, macrophages, B, and T-cells (107). The direct role of maternal soluble factors and immune cells consumed by the rapidly developing neonate is unknown, yet, it is tempting to speculate that these factors aid in the establishment and development of microbial communities in the infant gut, while promoting defense against harmful pathogens (108). Regardless of exact immunological mechanisms, beneficial clinical effects from breastfeeding have been reported for both children and mothers.

Systematic review and meta-analysis of breastfeeding research in developed countries has shown that a history of breastfeeding is associated with a reduced risk of acute otitis media, non-specific gastroenteritis, sever lower respiratory tract infections, atopic dermatitis, asthma, obesity, type 1 diabetes, childhood leukemia, sudden infant death syndrome, and necrotizing enterocolitis (109). Beneficial maternal outcomes were also associated with lactation, and reduction of risk for development of type 2 diabetes, breast cancer, and ovarian cancer. Premature cessation of breastfeeding or not breastfeeding was associated with an increased risk for post-partum depression (109). It is noteworthy that this analysis was based on observational studies and does not imply causality. Breastfeeding is important for nutrition and education of the neonatal immune system.

\section{PERINATAL NUTRITIONAL IMPACT}

The relationship between nutritional status and immunological competence is a matter of debate. Nutritional deprivation has likely been common throughout our evolution history, thus, selective processes hypothetically favor resilient immune systems that are not impaired by transient episodes of malnutrition (110). However, our current population density, global interdependency, and modern lifestyles represent a mismatch between the selective pressures historically acting on our immune systems and the exposures we face today. In addition, our concern is with promoting immune health for life, which does not equate with the role of diet and immunity required for maximum reproductive fitness. High adherence to the Mediterranean diet during the perinatal period is protective against wheeze and atopy in children (111), demonstrating that maternal diet may be of import not 
only for the specific caloric and nutritional need of the developing fetus but also for offspring immune modulation (112). Mechanistically neonatal immune programing can take place in utero given that food and environment antigen specific T-cell responses are detectable in virtually all neonatal cord blood samples (113). Nutrition may be the source of antigens to which the immune system must become tolerant, and additionally provide factors that themselves modulate immune activity (113). The interrelationship between nutrition and immunity is highly complex; however, there are known nutritional deficiencies that can influence immune activity early in life though these may indeed be transient effects and not lead to lifelong disease susceptibility.

\section{MICRONUTRIENTS}

Hallmarks of malnutrition include micronutrient limitations and protein-calorie macronutrient deficiencies. Full reviews on micronutrient malnutrition and immunity can be found elsewhere (114-116) and only select micronutrients (selenium, zinc, and vitamin A) known to modulate immunity are highlighted here. Limited maternal dietary selenium also restricts transmission to the neonate that has been reported to result in impaired in vitro activation of thymocytes, and decreased proportions of circulating adaptive immune cells in the neonate (117). Zinc deficiency has been associated with impaired growth and immune cell functions (118) and reprograming of the immune system from adaptive to more innate immune responses (119). Randomized controlled trials of zinc supplementation in small for gestational age term infants have resulted in decreases in diarrhea, pneumonia infection, and may reduce overall mortality in some settings (120). Vitamin A is crucial for integrity of barriers, lymphocyte proliferation, and cytotoxic T-cell activity, deficiency reduces the number of circulating immune cells and complement proteins (121). Broad supplementation of micronutrients may not reduce undesirable outcomes, because nutrient-nutrient interactions may increase or decrease availability of other immune modulatory nutrients altering nutritional homeostasis (121). Explicit deficit may not temper immunity but rather a dietary imbalance could be the culprit. Micronutrient deficiencies are plausible modulators of immunity, though the immune modulation based on micronutrient deficiency appears to be transient and in that subsequent supplementation can rescue immune system functionality.

\section{MACRONUTRIENTS}

Study of human macronutrient deficiencies primarily arises from tragic natural experiments, wherein populations suffer acute or seasonal periods of starvation. The immune system appears to be intrinsically tied to metabolic functions, and depending on timing of macronutrient deficiency may have long-term implications due to lasting epigenetic modifications (122). Study of immune outcome in such settings is intrinsically difficult, and results are primarily based upon retrospective analysis of records rather than controlled experimental settings.

An incredibly thorough retrospective analysis of perinatal acute famine comes from Holland during WWII, during which comprehensive records were kept about famine exposure, pregnancy, and the development of the newborns (123). In utero exposure to famine resulted in lower birth weights, later increased rates of mental illness (schizophrenia and antisocial personality disorder), congenital neural defects, obstructive airway disease, coronary heart disease, altered renal function, fivefold increases in breast cancer risk among women and reduced glucose and insulin tolerance (124). Famine exposure effects were not limited to the first generation, but were carried forward into the subsequent generation. Adult offspring born to prenatally undernourished fathers (but not mothers) were on average $5 \mathrm{~kg}$ heavier than peers born to unexposed fathers (125). Lasting effects on immunity are implied by heritable metabolic differences, as obesity has been associated with altered baseline inflammation (126). Additionally, records from a Swedish community have revealed that grand-paternal exposure to poor food availability during his prepubescent and slow growth period resulted in a fourfold increase in grandchild risk for diabetes, however, no underlying mechanism explaining the process was described (127). Thus, even relatively transient exposures to starvation may have intergenerational implications for metabolism, and by proxy, immune status.

Other studies focused on primary immune outcomes and nutrient deficit have produced incongruent results. In the Philippines, 14-15 year olds born with small for gestational age birth (related to intrauterine growth restriction) and lasting nutritional deficit have a lower probability of responding to typhoid vaccines than their peers (128). In contrast, assessment of immune implications from perinatal (seasonal) nutritional deprivation in the Gambia later in life (18-24-year-old men) revealed no lasting effect on the proportion of memory and naive T-cells (129). The timing, nature, and duration of perinatal nutritional deficit impacts human immune development in different ways; however, these effects are additionally confounded by local genetics, toxin exposures, cultural practices, and exposure to both inert and infectious organisms.

\section{HYGIENE HYPOTHESIS AND MICROBIAL EXPOSURES}

The hygiene hypothesis has expanded from initial observations of allergy and social position to include assessment of observed increases in inflammatory diseases, atopy, and allergy inversely correlated with risk of infectious disease and parasite burden (130). During pregnancy the maternal compartment provides nutrition and immune defenses for the neonate and influences microbial colonization. Maternal involvement in microbial colonization may be from in utero exposure, acquisition during childbirth, and transmission through breast milk.

There is ample evidence suggesting that the womb and developing fetus are not sterile, thus, it may be the case that neonatal tolerance to certain microbes may begin before birth. Clinical evidence from perinatal infections implies that the womb is not perfectly sterile, and bacteria may invade the uterus from the abdominal cavity, blood, or the cervix (131). Aside from clinical description of pathology, the presence of bacterial DNA in the placenta of healthy vaginal and caesarian births has been reported $(131,132)$. Bacteria have been detected in umbilical cord blood from elective cesarean section, in the meconium of healthy term births from mothers who had not had probiotic supplementation who had not yet been breastfed, and even in the amniotic fluid of a murine model (133). While the womb may not be sterile and be 
the stage for limited in utero microbial exposures, the vast majority and continued interaction with microbes takes place post-partum.

\section{MODE OF DELIVERY}

As the neonate transitions from the intrauterine environment into the external environment rapid colonization takes place, influenced by mode of birth. Cesarean and vaginal birth result in different microbes initially colonizing the neonate, either reflecting maternal skin and local surface or vaginal microbes, respectively $(134,135)$. Clinically, children born by cesarean delivery are more likely to suffer from rhinitis, asthma, type 1 diabetes, and celiac disease $(136,137)$. Vaginal delivery promotes production of numerous cytokines and associated soluble receptors (IL-6, IL-1Beta, sIL-2R, sIL4R, interferon-gamma, and tumor necrosis factor alpha) in both maternal serum and neonatal umbilical cord blood, which are related to immune activation (138). The promotion of these cytokines supports the notion that vaginal birth activates both maternal and neonatal immune system in a proinflammatory manner. This response is likely important for initial colonization of the neonate by microbes, and increase in cesarean delivery associated immune dysfunction may be due to altered microbial exposures and baseline inflammation status of both neonate and maternal systems. Post-partum, neonatal gut microbiome composition is likely continually influenced by breast milk that according to culture dependent, independent, and metagenomic methods harbors a diverse community of bacteria (139, 140).

\section{MICROBIOTA, DISEASE, AND TRAINED IMMUNITY}

Continued interaction with microbes that live upon and within us represents a most intimate environmental exposure and challenge for the immune system. The microbiota colonizing human gut, skin, and mucosal membranes are integral for energy harvest from food sources (141), metabolism $(142,143)$, and are implied in the education of the immune system $(144,145)$. Microbes and microbial communities have been implicated in a variety of diseases that include immune involvement including severe malnutrition (146), obesity $(142,143,147)$, chronic obstructive pulmonary disorder (148), and irritable bowl disease (149). Animal models reveal that the gut microbiota directly interact with immune activity by changing the proportion of gut mRNA for chemokines, receptors, and FoxP3 (associated with regulatory T-cells) (150). More comprehensive reviews on the impact of human microbiota in early life are provided elsewhere $(144,151)$. To date, there has been limited research assessing the role of eukaryotes in microbial communities, further research of which are required to fully describe complex gut ecosystems in order to understand the role of the microbiome in health and disease. The human gut microbiome is acquired from local environments and is variable depending on numerous environmental influences, including geography, diet, and lifestyle (152).

The human microbiota appears to have some implications in human health and disease, likely through participation in immunological education. Early life microbial exposure may be exceedingly important within the context of trained innate immunity. In this process, independent of adaptive immune mechanisms primary exposure to pathogen can alter innate immune cell programed responses to subsequent re-exposure. Depending on the stimuli, exposure can result in innate cell training with resulting heightened or attenuated cytokine responses, lasting programing occurs through epigenetic histone modification (153). Both murine and human studies indicate innate immune system responses are altered by repeated exposure to the same pathogen (154). Innate immune cells can be trained by prior exposures, and can influence the success of vaccines (18). It is of critical importance to better understand how microbial exposure can alter both trained and adaptive arms of the immune system to promote adequate immune education for life-long health.

\section{GLOBAL VARIATION IN EARLY LIFE IMMUNITY}

Humans have incredibly plastic immune responses to the myriad of toxic, infectious, nutritional, and microbial exposures encountered throughout life. With added genetic variability, it is no wonder that promoting global health has been an ongoing struggle. Age-related patterns in innate immunity development vary depending on the area assessed $(155,156)$. In efforts to describe global innate immunity Smolen et al. enrolled subjects from four continents and assessed pattern recognition receptor mediated responses. Despite environmental variation between continents toll-like receptor mediated cytokine production was remarkable similar in most sites, with only South African subjects appearing as obvious outliers, though nuanced differences were present between all populations (157). Whether they may be drastic or nuanced differences, understanding how populations response to immune stimuli may be of critical importance for explaining global variation in vaccine efficacy. Global and regional assessment of local immune responses will be fundamental for developing new and optimizing current vaccines.

\section{VARIABLE VACCINE RESPONSE}

Even when cold chain and distribution requirements are adequately met vaccines are not ubiquitously successful. One of the best studied and most globally relevant examples of geographic variation in immune system function are the response to vaccination with bacille Calmette-Guerin (BCG) against tuberculosis (TB). Widely used with variable outcomes, a comprehensive metaanalysis of BCG has shown that it reduces tuberculosis risk by $50 \%$ (158), but provides no protection in some parts of the world (159). A review of BCG trials found latitude to be strongly associated with protection, explaining $41 \%$ of the variance between studies (159). A more recent meta-analysis revealed that protection was higher in trials further from the equator, in areas with lower risk of diagnostic detection bias, and when studies address potential confounding of latent mycobacterial exposure (160).

There are many hypotheses for the variable efficacy of BCG against pulmonary tuberculosis, including vaccine substrain over attenuation, inadequate dosage, interference by prior exposure to Mycobacterium, host genetics, and geographic differences in clinical isolates (161). Northern Malawi is an area where BCG does not appear to have substantial protective effects, and prior environmental exposure to mycobacterial antigens appears to prevent replication of BCG within the host (162). Additional research assessing cytokine production induced by vaccination showed UK 
subjects (who are protected by vaccine) exhibited Th1 associated cytokines, whereas Malawian subjects with poor protection from vaccine had Th2 and IL-17 biased responses (163).

Differences in BCG strains have been well assessed and have been found to lead to differential gene regulation and efficacy, but no one strain appears to be consistently superior in all locations and for both pulmonary and disseminated TB (164). Restimulation of peripheral mononuclear blood cells from Mexican neonates vaccinated with different BCG stains displayed significantly different levels of interferon-gamma, IL-12B, IL27, IL-1, IL-6, and IL-24 mRNA (165). Ultimately, any and all the hypotheses likely have some credence, and determining the best course of action will have to consider local genetics and environmental exposures to optimize vaccine efficacy and disease prevention. Unfortunately, this means no single vaccine is likely to confer protection to all of humanity. However, assessment of local immune responses to stimuli may enable derivation of customized adjuvants to adequately activate the immune system to confer lasting protection.

Despite contrary results for the protective effects of BCG against tuberculosis, vaccination is recommended to continue due to reduced infection from other mycobacteria as well as astonishing non-specific effects that have been recently noted in a randomized clinical trial in premature births in Guinea-Bissau. Overall child mortality was reduced by over $50 \%$ when low birth-weight children who received BCG earlier than currently recommended (166). It is important to note that though BCG vaccination may have beneficial non-specific effects, it can also modulate immune responses to subsequent vaccination (167). Non-specific effects of vaccines are not limited to BCG, but have also been reported for measles, and DTP (diphtheria, pertussis, and tetanus) vaccines; it has been suggested that optimization of immune scheduling in areas with high infectious disease burden could reduce child mortality by $30 \%$ (168). Optimization of existing vaccine scheduling may seem to be low hanging fruit, but will require thorough analysis of local immune development with consideration of both genetic and environmental factors.

\section{SEASONALITY}

Though an individual may remain geographically constrained their environmental exposures may vary dramatically depending on seasonal. Changing temperature, rainfall, exposure to elements, food availability, diet, and exposure to infectious agents may be compounded or alleviated by local cultural practice. Perturbation of immune function early in life may have important short-term impacts as both birth season and nutritional status have been associated with decreased humoral response to pertussis vaccination (169). Birth during the wet season in West Africa increases the proportion of T-cells in the CD8+ compartment, decreasing the CD4+:CD8+ ratio $(170,171)$. In rural Gambia, season of birth has been associated with infection related adult mortality and was postulated to be due to perinatal nutritional status or pathogen exposure during early immune programing (172). However, no association between seasonality and immune status was detected in a subsequent study of youth (173) or young adults (129). Independent of nutrition or pathogen exposure, seasonality can also change diurnal exposure to sunlight and levels of circulating vitamin D. In the United Kingdom, vitamin D status during gestation and birth month has been associated with diseases with immune involvement, including rheumatoid arthritis, irritable bowel diseases, and multiple sclerosis (174). Assessment of seasonality, vitamin $\mathrm{D}$, and infectious disease has been further explored with regards to TB in South Africa, revealing a reciprocal seasonal variation in serum $25(\mathrm{OH}) \mathrm{D}$ concentration and $\mathrm{TB}$ notification (175). Seasonality is a multifactorial parameter to be considered for studies of human immunity, though evidence for long-term immune programing is limited.

\section{CONCLUSION}

Numerous environmental factors can modulate human immunity early in life. These range from abiotic chemicals exposures and nutritional status to biotic insult from infectious diseases and with microbial or parasitic colonization. Early life represents windows of both vulnerability and opportunity that impact the developing immune system. The cases above demonstrate that there can be short-term and lasting implications for lifelong health based on pre- and perinatal environmental exposures. These include potential inherited programing (genetic and epigenetic), derailed development due to altered metabolism (nutrition and toxicology), and inappropriate immune system decision-making (for both adaptive and innate arms).

A living world is defined by change, in terms of both environment and human populations. It is fitting that the immune system is in a constant state of flux to adapt to local constraints and conditions. Though selective pressures of environments have shaped the evolution of our immune systems, in recent years we have rapidly altered our lifestyle and environments. As a result, today we live in a world foreign to our ancestors. Given the inherent plasticity of the immune system, it follows that with exposure to entirely different organisms and chemicals than those we coexisted with for the last millenia can result in undesirable outcomes. Through medical interventions we are also living much longer lives, beyond the threshold of selective pressure. In order to promote immune-mediated health for life, we must consider the importance of environmental exposures for immune programing, and learn how to direct the developing immune system to optimize health outcomes. For example, the result of perinatal toxic exposures highlight the need to include assessment of the developing immune system for modulation in animal models beyond short-term adult toxicity, and include multi-generational monitoring. This also suggests surveillance of human populations need to be conducted for longer periods of time, to determine whether chemical exposures are hazardous for immune health in different physiologically relevant combinations and over time. And while we only recently have begun to understand that the microbiome is likely centrally involved in a number of chronic diseases, such profound and wide-spread impact highlights the power of microbial exposure in early life to modulate developmental trajectories. For example, it appears possible to reduce global morbidity and mortality with targeted early life probiotic interventions, as has been recently suggested in preliminary results from an active yogurt culture study in India (176).

Bass Becking and Beijerinck once stated that "everything is everywhere; but the environment selects" (177). We would like 
to add to this phrase "and we adapt." To enable continued survival the human immune system must be especially malleable early in life, to respond to rapidly changing requirements between prenatal and postnatal life. Adaptability is the hallmark of both innate and adaptive immunity and through immune memory, can direct life-long immune-mediated health. Though there remains much to be done to determine how to best to direct the immune system toward optimal long-term health, we now have gathered a critical mass of insight into the mechanisms underlying immune programing in early life and with that for the first time are presented with the unprecedented opportunity to become stewards of not only prevention of disease but also promotion of life-long health.

\section{ACKNOWLEDGMENTS}

Funding: Tobias R. Kollmann is supported in part by a Career Award in the Biomedical Sciences from the Burroughs Wellcome Fund and a Michael Smith Foundation for Health Research Career Investigator Award.

\section{REFERENCES}

1. Orkin SH, Zon LI. Hematopoiesis: an evolving paradigm for stem cell biology. Cell (2008) 132(4):631-44. doi:10.1016/j.cell.2008.01.025

2. Cumano A, Dieterlen-Lievre F, Godin I. Lymphoid potential, probed before circulation in mouse, is restricted to caudal intraembryonic splanchnopleura. Cell (1996) 86(6):907-16. doi:10.1016/S0092-8674(00)80166-X

3. Cumano A, Ferraz JC, Klaine M, Di Santo JP, Godin I. Intraembryonic, but not yolk sac hematopoietic precursors, isolated before circulation, provide long-term multilineage reconstitution. Immunity (2001) 15(3):477-85. doi:10.1016/S1074-7613(01)00190-X

4. Tavian M, Robin C, Coulombel L, Péault B. The human embryo, but not its yolk sac, generates lympho-myeloid stem cells: mapping multipotent hematopoietic cell fate in intraembryonic mesoderm. Immunity (2001) 15(3):487-95. doi:10.1016/S1074-7613(01)00193-5

5. Zambidis ET, Oberlin E, Tavian M, Péault B. Blood-forming endothelium in human ontogeny: lessons from in utero development and embryonic stem cell culture. Trends Cardiovasc Med (2006) 16(3):95-101. doi:10.1016/j.tcm.2006. 01.005

6. Sieweke MH, Allen JE. Beyond stem cells: self-renewal of differentiated macrophages. Science (2013) 342(6161):1242974-1242974. doi:10.1126/ science. 1242974

7. Ghazal P, Dickinson P, Smith CL. Early life response to infection. Curr Opin Infect Dis (2013) 26(3):213-8. doi:10.1097/QCO.0b013e32835fb8bf

8. Kollmann TR, Crabtree J, Rein-Weston A, Blimkie D, Thommai F, Wang XY, et al. Neonatal innate TLR-mediated responses are distinct from those of adults. J Immunol (2009) 183(11):7150-60. doi:10.4049/jimmunol.0901481

9. Levy O. Innate immunity of the newborn: basic mechanisms and clinical correlates. Nat Rev Immunol (2007) 7(5):379-90. doi:10.1038/nri2075

10. Kollmann T, Wilson C. Induction of antigen-specific immunity in human neonates and infants. In: Barker DJP, Bergmann R, Ogra PL, editors. The Window of Opportunity: Pre-Pregnancy to 24 Months of Age. (Vol. 61), Basel: Karger (2008). p. 183-95.

11. Wynn JL, Levy O. Role of innate host defenses in susceptibility to earlyonset neonatal sepsis. Clin Perinatol (2010) 37(2):307-37. doi:10.1016/j.clp. 2010.04.001

12. Corbett NP, Blimkie D, Ho KC, Cai B, Sutherland DP, Kallos A, et al. Ontogeny of toll-like receptor mediated cytokine responses of human blood mononuclear cells. PLoS One (2010) 5(11):e15041. doi:10.1371/journal.pone.0015041

13. Kollmann TR, Levy O, Montgomery RR, Goriely S. Innate immune function by toll-like receptors: distinct responses in newborns and the elderly. Immunity (2012) 37(5):771-83. doi:10.1016/j.immuni.2012.10.014

14. Wadhwa P, Buss C, Entringer S, Swanson J. Developmental origins of health and disease: brief history of the approach and current focus on epigenetic mechanisms. Semin Reprod Med (2009) 27(05):358-68. doi:10.1055/s-0029-1237424
15. Barouki R, Gluckman PD, Grandjean P, Hanson M, Heindel JJ. Developmental origins of non-communicable disease: implications for research and public health. Environ Health (2012) 11:42. doi:10.1186/1476-069X-11-42

16. Jirtle RL, Skinner MK. Environmental epigenomics and disease susceptibility. Nat Rev Genet (2007) 8(4):253-62. doi:10.1038/nrg2045

17. Portela A, Esteller M. Epigenetic modifications and human disease. Nat Biotechnol (2010) 28(10):1057-68. doi:10.1038/nbt.1685

18. Netea MG, Quintin J, van der Meer JW. Trained immunity: a memory for innate host defense. Cell Host Microbe (2011) 9(5):355-61. doi:10.1016/j.chom.2011. 04.006

19. Bruniquel D, Schwartz RH. Selective, stable demethylation of the interleukin2 gene enhances transcription by an active process. Nat Immunol (2003) 4(3):235-40. doi:10.1038/ni887

20. Northrop JK, Thomas RM, Wells AD, Shen H. Epigenetic remodeling of the IL2 and IFN- loci in memory CD8 T cells is influenced by CD4 T cells. J Immunol (2006) 177(2):1062-9. doi:10.4049/jimmunol.177.2.1062

21. Duramad P, Tager IB, Holland NT. Cytokines and other immunological biomarkers in children's environmental health studies. Toxicol Lett (2007) 172(1):48-59. doi:10.1016/j.toxlet.2007.05.017

22. Cabassi E. The immune system and exposure to xenobiotics in animals. Vet Res Commun (2007) 31(S1):115-20. doi:10.1007/s11259-007-0074-8

23. Gundacker $C$, Hengstschlãger $M$. The role of the placenta in fetal exposure to heavy metals. Wien Med Wochenschr (2012) 162(9-10):201-6. doi:10.1007/ s10354-012-0074-3

24. Vahter M. Effects of arsenic on maternal and fetal health. Annu Rev Nutr (2009) 29(1):381-99. doi:10.1146/annurev-nutr-080508-141102

25. Ritz B, Heinrich J, Wjst M, Wichmann E, Krause C. Effect of cadmium body burden on immune response of school children. Arch Environ Health (1998) 53(4):272-80. doi:10.1080/00039899809605708

26. Schwartz GG, Il'yasova D, Ivanova A. Urinary cadmium, impaired fasting glucose, and diabetes in the NHANES III. Diabetes Care (2003) 26(2):468-70. doi:10.2337/diacare.26.2.468

27. Bose-O'Reilly S, McCarty KM, Steckling N, Lettmeier B. Mercury exposure and children's health. Curr Probl Pediatr Adolesc Health Care (2010) 40(8):186-215. doi:10.1016/j.cppeds.2010.07.002

28. Chen Z, Myers R, Wei T, Bind E, Kassim P, Wang G, et al. Placental transfer and concentrations of cadmium, mercury, lead, and selenium in mothers, newborns, and young children. J Expo Sci Environ Epidemiol (2014) 24(5):537-44. doi:10.1038/jes.2014.26

29. Belles-Isles M, Ayotte P, Dewailly E, Weber J-P, Roy R. Cord blood lymphocyte functions in newborns from a remote maritime population exposed to organochlorines and methylmercury. J Toxicol Environ Health A (2002) 65(2):165-82. doi:10.1080/152873902753396794

30. Miller TE, Golemboski KA, Ha RS, Bunn T, Sanders FS, Dietert RR. Developmental exposure to lead causes persistent immunotoxicity in Fischer 344 rats. Toxicol Sci (1998) 42(2):129-35. doi:10.1093/toxsci/42.2.129

31. Ahmed S, Ahsan KB, Kippler M, Mily A, Wagatsuma Y, Hoque AMW, et al. In utero arsenic exposure is associated with impaired thymic function in newborns possibly via oxidative stress and apoptosis. Toxicol Sci (2012) 129(2):305-14. doi:10.1093/toxsci/kfs202

32. Koestler DC, Avissar-Whiting M, Houseman EA, Karagas MR, Marsit CJ. Differential DNA methylation in umbilical cord blood of infants exposed to low levels of arsenic in utero. Environ Health Perspect (2013) 121(8):971-7. doi:10.1289/ehp.1205925

33. Dangleben NL, Skibola CF, Smith MT. Arsenic immunotoxicity: a review. Environ Health (2013) 12(1):73. doi:10.1186/1476-069X-12-73

34. Intarasunanont $P$, Navasumrit $P$, Woraprasit $S$, Chaisatra K, Suk WA, Mahidol C, et al. Effects of arsenic exposure on DNA methylation in cord blood samples from newborn babies and in a human lymphoblast cell line. Environ Health (2012) 11(1):31. doi:10.1186/1476-069X-11-31

35. Kile ML, Baccarelli A, Hoffman E, Tarantini L, Quamruzzaman Q, Rahman M, et al. Prenatal arsenic exposure and DNA methylation in maternal and umbilical cord blood leukocytes. Environ Health Perspect (2012) 120(7):1061-6. doi:10.1289/ehp.1104173

36. Lu K, Abo RP, Schlieper KA, Graffam ME, Levine S, Wishnok JS, et al. Arsenic exposure perturbs the gut microbiome and its metabolic profile in mice: an integrated metagenomics and metabolomics analysis. Environ Health Perspect (2014) 122(3):284-91. doi:10.1289/ehp.1307429 
37. Dekoning E, Karmaus W. PCB exposure in utero and via breast milk. A review. J Expo Anal Environ Epidemiol (2000) 10:3. doi:10.1038/sj.jea.7500090

38. Fromme H, Mosch C, Morovitz M, Alba-Alejandre I, Boehmer S, Kiranoglu $\mathrm{M}$, et al. Pre- and postnatal exposure to perfluorinated compounds (PFCs). Environ Sci Technol (2010) 44(18):7123-9. doi:10.1021/es101184f

39. Holladay SD. Prenatal immunotoxicant exposure and postnatal autoimmune disease. Environ Health Perspect (1999) 107(Suppl 5):687. doi:10.2307/3434328

40. Needham LL, Grandjean P, Heinzow B, Jørgensen PJ, Nielsen F, Patterson DG Jr, et al. Partition of environmental chemicals between maternal and fetal blood and tissues. Environ Sci Technol (2010) 45(3):1121-6. doi:10.1021/ es1019614

41. Baccarelli A, Giacomini SM, Corbetta C, Landi MT, Bonzini M, Consonni D, et al. Neonatal thyroid function in Seveso 25 years after maternal exposure to dioxin. PLoS Med (2008) 5(7):e161. doi:10.1371/journal.pmed.0050161

42. Bruner-Tran KL, Osteen KG. Developmental exposure to TCDD reduces fertility and negatively affects pregnancy outcomes across multiple generations. Reprod Toxicol (2011) 31(3):344-50. doi:10.1016/j.reprotox.2010.10.003

43. Corsini E, Avogadro A, Galbiati V, dell'Agli M, Marinovich M, Galli CL, et al. In vitro evaluation of the immunotoxic potential of perfluorinated compounds (PFCs). Toxicol Appl Pharmacol (2011) 250(2):108-16. doi:10.1016/ j.taap.2010.11.004

44. Grandjean P, Andersen EW, Budtz-Jørgensen E, Nielsen F, Mølbak KA, Weihe $\mathrm{P}$, et al. Serum vaccine antibody concentrations in children exposed to perfluorinated compounds. JAMA (2012) 307(4):391-7. doi:10.1001/jama.2011.2034

45. Hertz-Picciotto I, Park H-Y, Dostal M, Kocan A, Trnovec T, Sram R. Prenatal exposures to persistent and non-persistent organic compounds and effects on immune system development. Basic Clin Pharmacol Toxicol (2008) 102(2):146-54. doi:10.1111/j.1742-7843.2007.00190.x

46. Heilmann C, Grandjean P, Weihe P, Nielsen F, Budtz-Jørgensen E. Reduced antibody responses to vaccinations in children exposed to polychlorinated biphenyls. PLoS Med (2006) 3(8):e311. doi:10.1371/journal.pmed.0030311

47. Glynn A, Thuvander A, Aune M, Johannisson A, Darnerud P, Ronquist G, et al. Immune cell counts and risks of respiratory infections among infants exposed pre- and postnatally to organochlorine compounds: a prospective study. Environ Health (2008) 7(1):62. doi:10.1186/1476-069X-7-62

48. Weisglas-Kuperus N, Patandin S, Berbers GA, Sas TC, Mulder PG, Sauer PJ, et al. Immunologic effects of background exposure to polychlorinated biphenyls and dioxins in Dutch preschool children. Environ Health Perspect (2000) 108(12):1203. doi:10.1289/ehp.001081203

49. Ogura I. Half-life of each dioxin and PCB congener in the human body. Organohalogen Compd (2004) 66:3376-80.

50. Ornoy A, Ergaz Z. Alcohol abuse in pregnant women: effects on the fetus and newborn, mode of action and maternal treatment. Int J Environ Res Public Health (2010) 7(2):364-79. doi:10.3390/ijerph7020364

51. Johnson S, Knight R, Marmer DJ, Steele RW. Immune deficiency in fetal alcohol syndrome. Pediatr Res (1981) 15(6):908-11. doi:10.1203/00006450198106000-00005

52. Gauthier TW, Drews-Botsch C, Falek A, Coles C, Brown LAS. Maternal alcohol abuse and neonatal infection. Alcohol Clin Exp Res (2005) 29(6):1035-43. doi:10.1097/01.ALC.0000167956.28160.5E

53. Pal-Bhadra M, Bhadra U, Jackson DE, Mamatha L, Park P-H, Shukla SD. Distinct methylation patterns in histone h3 at lys-4 and lys-9 correlate with up- and down-regulation of genes by ethanol in hepatocytes. Life Sci (2007) 81(12):979-87. doi:10.1016/j.lfs.2007.07.030

54. Sathyan P, Golden HB, Miranda RC. Competing interactions between microRNAs determine neural progenitor survival and proliferation after ethanol exposure: evidence from an ex vivo model of the fetal cerebral cortical neuroepithelium. J Neurosci (2007) 27(32):8546-57. doi:10.1523/JNEUROSCI.126907.2007

55. Wilhelm-Benartzi CS, Houseman EA, Maccani MA, Poage GM, Koestler DC, Langevin SM, et al. In utero exposures, infant growth, and DNA methylation of repetitive elements and developmentally related genes in human placenta. Environ Health Perspect (2011) 120(2):296-302. doi:10.1289/ehp.1103927

56. Hofhuis W, De Jongste JC, Merkus P. Adverse health effects of prenatal and postnatal tobacco smoke exposure on children. Arch Dis Child (2003) 88(12):1086-90. doi:10.1136/adc.88.12.1086

57. Strachan DP, Cook DG. Health effects of passive smoking. 1. Parental smoking and lower respiratory illness in infancy and early childhood. Thorax (1997) 52(10):905-14. doi:10.1136/thx.52.10.905
58. Noakes PS. Maternal smoking is associated with impaired neonatal tolllike-receptor-mediated immune responses. Eur Respir J (2006) 28(4):721-9. doi:10.1183/09031936.06.00050206

59. Herberth G, Bauer M, Gasch M, Hinz D, Rãder S, Olek S, et al. Maternal and cord blood miR-223 expression associates with prenatal tobacco smoke exposure and low regulatory T-cell numbers. J Allergy Clin Immunol (2014) 133(2):543-50. doi:10.1016/j.jaci.2013.06.036

60. DeWitt JC, Peden-Adams MM, Keil DE, Dietert RR. Current status of developmental immunotoxicity: early-life patterns and testing. Toxicol Pathol (2012) 40(2):230-6. doi:10.1177/0192623311427709

61. Dietert RR. Developmental immunotoxicology: focus on health risks. Chem Res Toxicol (2009) 22(1):17-23. doi:10.1021/tx800198m

62. Trowsdale J, Betz AG. Mother's little helpers: mechanisms of maternal-fetal tolerance. Nat Immunol (2006) 7(3):241-6. doi:10.1038/nrm1922

63. Juch H, Blaschitz A, Dohr G, Hutter H. HLA class I expression in the human placenta. Wien Med Wochenschr (2012) 162(9-10):196-200. doi:10.1007/s10354012-0070-7

64. Carosella ED, Paul P, Moreau P, Rouas-Freiss N. HLA-G and HLA-E: fundamental and pathophysiological aspects. Immunol Today (2000) 21(11):532-4. doi:10.1016/S0167-5699(00)01707-2

65. Hunt JS. HLA-g and immune tolerance in pregnancy. FASEB $J$ (2005) 19(7):681-93. doi:10.1096/fj.04-2078rev

66. Munn DH, Zhou M, Attwood JT, Bondarev I, Conway SJ, Marshall B, et al. Prevention of allogeneic fetal rejection by tryptophan catabolism. Science (1998) 281(5380):1191-3. doi:10.1126/science.281.5380.1191

67. Rowe JH, Ertelt JM, Aguilera MN, Farrar MA, Way SS. Foxp3+ regulatory T cell expansion required for sustaining pregnancy compromises host defense against prenatal bacterial pathogens. Cell Host Microbe (2011) 10(1):54-64. doi:10.1016/j.chom.2011.06.005

68. Robinson DP, Klein SL. Pregnancy and pregnancy-associated hormones alter immune responses and disease pathogenesis. Horm Behav (2012) 62(3):263-71. doi:10.1016/j.yhbeh.2012.02.023

69. de Man YA, Dolhain RJEM, van de Geijn FE, Willemsen SP, Hazes JMW. Disease activity of rheumatoid arthritis during pregnancy: results from a nationwide prospective study. Arthritis Rheum (2008) 59(9):1241-8. doi:10.1002/art.24003

70. Østensen M, Villiger PM, Förger F. Interaction of pregnancy and autoimmune rheumatic disease. Spec Issue Gend Sex Horm Pregnancy Autoimmun (2012) 11(6-7):A437-46. doi:10.1016/j.autrev.2011.11.013

71. Kourtis AP, Read JS, Jamieson DJ. Pregnancy and infection. NEngl J Med (2014) 370(23):2211-8. doi:10.1056/NEJMra1213566

72. Sappenfield E, Jamieson DJ, Kourtis AP. Pregnancy and susceptibility to infectious diseases. Infect Dis Obstet Gynecol (2013) 2013:1-8. doi:10.1155/2013/ 752852

73. Beeson JG, Brown GV, Molyneux ME, Mhango C, Dzinjalamala F, Rogerson SJ. Plasmodium falciparum isolates from infected pregnant women and children are associated with distinct adhesive and antigenic properties. J Infect Dis (1999) 180(2):464-72. doi:10.1086/314899

74. Mens PF, Bojtor EC, Schallig HD. Molecular interactions in the placenta during malaria infection. Eur J Obstet Gynecol Reprod Biol (2010) 152(2):126-32. doi:10.1016/j.ejogrb.2010.05.013

75. Kraus TA, Engel SM, Sperling RS, Kellerman L, Lo Y, Wallenstein S, et al. Characterizing the pregnancy immune phenotype: results of the viral immunity and pregnancy (VIP) study. J Clin Immunol (2012) 32(2):300-11. doi:10.1007/ s10875-011-9627-2

76. Robbins JR, Bakardjiev AI. Pathogens and the placental fortress. Curr Opin Microbiol (2012) 15(1):36-43. doi:10.1016/j.mib.2011.11.006

77. Strunk T, Currie A, Simmer K, Burgner D. Chronic maternal infections during pregnancy. Lancet Infect Dis (2012) 12(10):747-8. doi:10.1016/S1473-3099(12) 70228-1

78. Dauby N, Goetghebuer T, Kollmann TR, Levy J, Marchant A. Uninfected but not unaffected: chronic maternal infections during pregnancy, fetal immunity, and susceptibility to postnatal infections. Lancet Infect Dis (2012) 12(4):330-40. doi:10.1016/S1473-3099(11)70341-3

79. LaBeaud AD, Malhotra I, King MJ, King CL, King CH. Do antenatal parasite infections devalue childhood vaccination? PLoS Negl Trop Dis (2009) 3(5):e442. doi:10.1371/journal.pntd.0000442

80. Lammie PJ, Hitch WL, Walker EM, Hightower AW, Eberhard ML. Maternal filarial infection as risk factor for infection in children. Lancet (1991) 337(8748):1005-6. doi:10.1016/0140-6736(91)92661-K 
81. Malhotra I, Mungai PL, Wamachi AN, Tisch D, Kioko JM, Ouma JH, et al. Prenatal T cell immunity to Wuchereria bancrofti and its effect on filarial immunity and infection susceptibility during childhood. J Infect Dis (2006) 193(7):1005-13. doi:10.1086/500472

82. Malhotra I, Ouma JH, Wamachi A, Kioko J, Mungai P, Njzovu M, et al. Influence of maternal filariasis on childhood infection and immunity to Wuchereria bancrofti in Kenya. Infect Immun (2003) 71(9):5231-7. doi:10.1128/IAI.71.9. 5231-5237.2003

83. Guadalupe I, Mitre E, Benitez S, Chico ME, Nutman TB, Cooper PJ. Evidence for in utero sensitization to Ascaris lumbricoides in newborns of mothers with ascariasis. J Infect Dis (2009) 199(12):1846-50. doi:10.1086/599214

84. Mehta RS, Rodriguez A, Chico M, Guadalupe I, Broncano N, Sandoval C, et al. Maternal geohelminth infections are associated with an increased susceptibility to geohelminth infection in children: a case-control study. PLoS Negl Trop Dis (2012) 6(7):e1753. doi:10.1371/journal.pntd.0001753

85. MacDonald AS. Immunology of parasitic helminth infections. Infect Immun (2002) 70(2):427-33. doi:10.1128/IAI.70.2.427-433.2002

86. Kamal SM, El Sayed Khalifa K. Immune modulation by helminthic infections: worms and viral infections. Parasite Immunol (2006) 28(10):483-96. doi:10.1111/j.1365-3024.2006.00909.x

87. Cooper PJ, Chico M, Sandoval C, Espinel I, Guevara A, Levine MM, et al. Human infection with Ascaris lumbricoides is associated with suppression of the interleukin-2 response to recombinant cholera toxin b subunit following vaccination with the live oral cholera vaccine CVD 103-HgR. Infect Immun (2001) 69(3):1574-80. doi:10.1128/IAI.69.3.1574-1580.2001

88. van Riet E, Hartgers FC, Yazdanbakhsh M. Chronic helminth infections induce immunomodulation: consequences and mechanisms. Immunobiology (2007) 212(6):475-90. doi:10.1016/j.imbio.2007.03.009

89. Sabin EA, Araujo MI, Carvalho EM, Pearce EJ. Impairment of tetanus toxoidspecific THl-like immune responses in humans infected with Schistosoma mansoni. J Infect Dis (1996) 173(1):269-72. doi:10.1093/infdis/173.1.269

90. Urban JF Jr, Steenhard NR, Solano-Aguilar GI, Dawson HD, Iweala OI, Nagler $\mathrm{CR}$, et al. Infection with parasitic nematodes confounds vaccination efficacy. Vet Parasitol (2007) 148(1):14-20. doi:10.1016/j.vetpar.2007.05.006

91. Gallagher M, Malhotra I, Mungai PL, Wamachi AN, Kioko JM, Ouma JH, et al. The effects of maternal helminth and malaria infections on motherto-child HIV transmission. AIDS (2005) 19(16):1849-55. doi:10.1097/01.aids. $0000189846.90946 .5 \mathrm{~d}$

92. Gebreegziabiher D, Desta K, Desalegn G, Howe R, Abebe M. The effect of maternal helminth infection on maternal and neonatal immune function and immunity to tuberculosis. PLoS One (2014) 9(4):e93429. doi:10.1371/journal. pone.0093429

93. Slogrove A, Reikie B, Naidoo S, De Beer C, Ho K, Cotton M, et al. HIV-exposed uninfected infants are at increased risk for severe infections in the first year of life. J Trop Pediatr (2012) 58(6):505-8. doi:10.1093/tropej/fms019

94. Afran L, Garcia Knight M, Nduati E, Urban BC, Heyderman RS, Rowland-Jones SL. HIV-exposed uninfected children: a growing population with a vulnerable immune system? HEU children: a vulnerable immune system? Clin Exp Immunol (2014) 176(1):11-22. doi:10.1111/cei.12251

95. Reikie BA, Adams RCM, Leligdowicz A, Ho K, Naidoo S, Ruck CE, et al. Altered innate immune development in HIV-exposed uninfected infants. J Acquir Immune Defic Syndr (2014) 66(3):245-55. doi:10.1097/QAI. 000000000000161

96. Reikie BA, Naidoo S, Ruck CE, Slogrove AL, de Beer C, La Grange H, et al. Antibody responses to vaccination among South African HIV-exposed and unexposed uninfected infants during the first 2 years of life. Clin Vaccine Immunol (2012) 20(1):33-8. doi:10.1128/CVI.00557-12

97. Abramczuk BM, Mazzola TN, Moreno YMF, Zorzeto TQ, Quintilio W, Wolf PS, et al. Impaired humoral response to vaccines among HIV-exposed uninfected infants. Clin Vaccine Immunol (2011) 18(9):1406-9. doi:10.1128/CVI. 05065- 11

98. Kidzeru EB, Hesseling AC, Passmore J-AS, Myer L, Gamieldien H, Tchakoute CT, et al. In-utero exposure to maternal HIV infection alters T-cell immune responses to vaccination in HIV-uninfected infants. AIDS (2014) 28(10):1421-30. doi:10.1097/QAD.0000000000000292

99. Kakkar F, Lamarre V, Ducruet T, Boucher M, Valois S, Soudeyns H, et al. Impact of maternal HIV-1 viremia on lymphocyte subsets among HIV-exposed uninfected infants: protective mechanism or immunodeficiency. BMC Infect Dis (2014) 14(1):236. doi:10.1186/1471-2334-14-236
100. Kuhn L, Meddows-Taylor S, Gray G, Tiemessen C. Human immunodeficiency virus (HIV)-specific cellular immune responses in newborns exposed to HIV in utero. Clin Infect Dis (2002) 34(2):267-76. doi:10.1086/338153

101. Arpadi S, Fawzy A, Aldrovandi GM, Kankasa C, Sinkala M, Mwiya M, et al. Growth faltering due to breastfeeding cessation in uninfected children born to HIV-infected mothers in Zambia. Am J Clin Nutr (2009) 90(2):344-53. doi:10.3945/ajcn.2009.27745

102. Kagaayi J, Gray RH, Brahmbhatt H, Kigozi G, Nalugoda F, Wabwire-Mangen F, et al. Survival of infants born to HIV-positive mothers, by feeding modality, in Rakai, Uganda. PLoS One (2008) 3(12):e3877. doi:10.1371/journal.pone. 0003877

103. Taha TE, Hoover DR, Chen S, Kumwenda NI, Mipando L, Nkanaunena K, et al. Effects of cessation of breastfeeding in HIV-1-exposed, uninfected children in Malawi. Clin Infect Dis (2011) 53(4):388-95. doi:10.1093/cid/cir413

104. Coutsoudis A. HIV, infant feeding and more perils for poor people: new WHO guidelines encourage review of formula milk policies. Bull World Health Organ (2008) 86(3):210-4. doi:10.2471/BLT.07.041679

105. Lãnnerdal B. Nutritional and physiologic significance of human milk proteins. Am J Clin Nutr (2003) 77(6):1537S-43S.

106. Garofalo R. Cytokines in human milk. J Pediatr (2010) 156(2):S36-40. doi:10.1016/j.jpeds.2009.11.019

107. Peroni DG, Chirumbolo S, Veneri D, Piacentini GL, Tenero L, Vella A, et al. Colostrum-derived $\mathrm{b}$ and $\mathrm{T}$ cells as an extra-lymphoid compartment of effector cell populations in humans. J Matern Fetal Neonatal Med (2013) 26(2):137-42. doi:10.3109/14767058.2012.733744

108. Field CJ. The immunological components of human milk and their effect on immune development in infants. J Nutr (2005) 135(1):1-4.

109. Ip S, Chung M, Raman G, Chew P, Magula N, DeVine D, et al. Breastfeeding and maternal and infant health outcomes in developed countries. Evid Rep Technol Assess (Full Rep) (2007) 153:1-186. doi:10.1542/gr.18-2-15

110. Morgan $\mathrm{G}$. What, if any, is the effect of malnutrition on immunological competence? Lancet (1997) 349(9066):1693-5. doi:10.1016/S0140-6736(96)12038-9

111. Chatzi L, Kogevinas M. Prenatal and childhood Mediterranean diet and the development of asthma and allergies in children. Public Health Nutr (2009) 12(9A):1629. doi:10.1017/S1368980009990474

112. West CE, Videky DJ, Prescott SL. Role of diet in the development of immune tolerance in the context of allergic disease. Curr Opin Pediatr (2010) 22(5):635-41. doi:10.1097/MOP.0b013e32833d96ef

113. Calder PC, Krauss-Etschmann S, de Jong EC, Dupont C, Frick J-S, Frokiaer $\mathrm{H}$, et al. Early nutrition and immunity - progress and perspectives. Br J Nutr (2006) 96(4):774-90. doi:10.1079/BJN20061917

114. Bhaskaram P. Micronutrient malnutrition, infection, and immunity: an overview. Nutr Rev (2002) 60:S40-5. doi:10.1301/00296640260130722

115. Kubena K, McMurray DN. Nutrition and the immune system: a review of nutrient-nutrient interactions. J Am Diet Assoc (1996) 96(11):1156-64. doi:10.1016/S0002-8223(96)00297-0

116. Palmer AC. Nutritionally mediated programming of the developing immune system. Adv Nutr (2011) 2(5):377-95. doi:10.3945/an.111.000570

117. Dylewski M, Mastro A, Picciano M. Maternal selenium nutrition and neonatal immune system development. Neonatology (2002) 82(2):122-7. doi:10.1159/ 000063088

118. Prasad AS. Discovery of human zinc deficiency: its impact on human health and disease. Adv Nutr (2013) 4(2):176-90. doi:10.3945/an.112.003210

119. Fraker PJ, King LE. Reprogramming of the immune system during zinc deficiency. Annu Rev Nutr (2004) 24(1):277-98. doi:10.1146/annurev.nutr.24. 012003.132454

120. Black RE. Zinc deficiency, infectious disease and mortality in the developing world. J Nutr (2003) 133(5):1485S-9S.

121. Goldenberg RL. The plausibility of micronutrient deficiency in relationship to perinatal infection. J Nutr (2003) 133(5):1645S-8S.

122. Amarasekera M, Prescott SL, Palmer DJ. Nutrition in early life, immuneprogramming and allergies: the role of epigenetics. Asian Pac J Allergy Immunol (2013) 31(3):175-82.

123. Roseboom T, de Rooij S, Painter R. The Dutch famine and its long-term consequences for adult health. Early Hum Dev (2006) 82(8):485-91. doi:10.1016/ j.earlhumdev.2006.07.001

124. Painter RC, Roseboom TJ, Bleker OP. Prenatal exposure to the Dutch famine and disease in later life: an overview. Reprod Toxicol (2005) 20(3):345-52. doi:10.1016/j.reprotox.2005.04.005 
125. Veenendaal M, Painter R, de Rooij S, Bossuyt P, van der Post J, Gluckman P, et al. Transgenerational effects of prenatal exposure to the 1944-45 Dutch famine. BJOG (2013) 120(5):548-54. doi:10.1111/1471-0528.12136

126. Gregor MF, Hotamisligil GS. Inflammatory mechanisms in obesity. Annu Rev Immunol (2011) 29(1):415-45. doi:10.1146/annurev-immunol-031210101322

127. Kaati G, Bygren LO, Edvinsson S. Cardiovascular and diabetes mortality determined by nutrition during parents' and grandparents' slow growth period. Eur J Hum Genet (2002) 10(11):682-8. doi:10.1038/sj.ejhg.5200859

128. McDade TW, Beck MA, Kuzawa C, Adair LS. Prenatal undernutrition, postnatal environments, and antibody response to vaccination in adolescence. Am J Clin Nutr (2001) 74(4):543-8.

129. Ghattas H, Wallace DL, Solon JA, Henson SM, Zhang Y, Ngom PT, et al. Longterm effects of perinatal nutrition on T lymphocyte kinetics in young Gambian men. Am J Clin Nutr (2007) 85(2):480-7.

130. Strachan DP. Hay fever, hygiene, and household size. BMJ (1989) 299(6710):1259. doi:10.1136/bmj.299.6710.1259

131. Epstein FH, Goldenberg RL, Hauth JC, Andrews WW. Intrauterine infection and preterm delivery. N Engl J Med (2000) 342(20):1500-7. doi:10.1056/ NEJM200005183422007

132. Steel JH, Malatos S, Kennea N, Edwards AD, Miles L, Duggan P, et al. Bacteria and inflammatory cells in fetal membranes do not always cause preterm labor. Pediatr Res (2005) 57(3):404-11. doi:10.1203/01.PDR.0000153869. 96337.90

133. Jiménez E, Fernández L, Marín ML, Martín R, Odriozola JM, Nueno-Palop $\mathrm{C}$, et al. Isolation of commensal bacteria from umbilical cord blood of healthy neonates born by cesarean section. Curr Microbiol (2005) 51(4):270-4. doi:10.1007/s00284-005-0020-3

134. Azad MB, Lissitsyn Y, Miller GE, Becker AB, HayGlass KT, Kozyrskyj AL. Influence of socioeconomic status trajectories on innate immune responsiveness in children. PLoS One (2012) 7(6):e38669. doi:10.1371/journal.pone.0038669

135. Dominguez-Bello MG, Costello EK, Contreras M, Magris M, Hidalgo G, Fierer $\mathrm{N}$, et al. Delivery mode shapes the acquisition and structure of the initial microbiota across multiple body habitats in newborns. Proc Natl Acad Sci U S A (2010) 107(26):11971-5. doi:10.1073/pnas.1002601107

136. Neu J, Rushing J. Cesarean versus vaginal delivery: long-term infant outcomes and the hygiene hypothesis. Clin Perinatol (2011) 38(2):321-31. doi:10.1016/ j.clp.2011.03.008

137. Khafipour E, Ghia J-E. Mode of delivery and inflammatory disorders. J Immunol Clin Res (2013) 1:1104.

138. Malamitsi-Puchner A, Protonotariou E, Boutsikou T, Makrakis E, Sarandakou A, Creatsas G. The influence of the mode of delivery on circulating cytokine concentrations in the perinatal period. Early Hum Dev (2005) 81(4):387-92. doi:10.1016/j.earlhumdev.2004.10.017

139. Fernández L, Langa S, Martín V, Maldonado A, Jiménez E, Martín R, et al. The human milk microbiota: origin and potential roles in health and disease. Pharmacol Res (2013) 69(1):1-10. doi:10.1016/j.phrs.2012.09.001

140. Ward TL, Hosid S, Ioshikhes I, Altosaar I. Human milk metagenome: a functional capacity analysis. BMC Microbiol (2013) 13(1):116. doi:10.1186/14712180-13-116

141. Turnbaugh PJ, Ley RE, Mahowald MA, Magrini V, Mardis ER, Gordon JI. An obesity-associated gut microbiome with increased capacity for energy harvest. Nature (2006) 444(7122):1027-31. doi:10.1038/nature05414

142. Musso G, Gambino R, Cassader M. Interactions between gut microbiota and host metabolism predisposing to obesity and diabetes. Annu Rev Med (2011) 62(1):361-80. doi:10.1146/annurev-med-012510-175505

143. Ridaura VK, Faith JJ, Rey FE, Cheng J, Duncan AE, Kau AL, et al. Gut microbiota from twins discordant for obesity modulate metabolism in mice. Science (2013) 341(6150):1241214-1241214. doi:10.1126/science.1241214

144. Round JL, Mazmanian SK. The gut microbiota shapes intestinal immune responses during health and disease. Nat Rev Immunol (2009) 9(5):313-23. doi:10.1038/nri2515

145. Sjögren YM, Tomicic S, Lundberg A, Böttcher MF, Björkstén B, SverremarkEkström E, et al. Influence of early gut microbiota on the maturation of childhood mucosal and systemic immune responses. Clin Exp Allergy (2009) 39(12):1842-51. doi:10.1111/j.1365-2222.2009.03326.x

146. Smith MI, Yatsunenko T, Manary MJ, Trehan I, Mkakosya R, Cheng J, et al. Gut microbiomes of Malawian twin pairs discordant for kwashiorkor. Science (2013) 339(6119):548-54. doi:10.1126/science.1229000
147. Finucane MM, Sharpton TJ, Laurent TJ, Pollard KS. A taxonomic signature of obesity in the microbiome? Getting to the guts of the matter. PLoS One (2014) 9(1):e84689. doi:10.1371/journal.pone.0084689

148. Sze MA, Dimitriu PA, Hayashi S, Elliott WM, McDonough JE, Gosselink JV, et al. The lung tissue microbiome in chronic obstructive pulmonary disease. Am J Respir Crit Care Med (2012) 185(10):1073-80. doi:10.1164/rccm.2011112075OC

149. Greenblum S, Turnbaugh PJ, Borenstein E. Metagenomic systems biology of the human gut microbiome reveals topological shifts associated with obesity and inflammatory bowel disease. Proc Natl Acad Sci U S A (2012) 109(2):594-9. doi:10.1073/pnas.1116053109

150. Meurens F, Berri M, Siggers RH, Willing BP, Salmon H, Van Kessel AG, et al. Commensal bacteria and expression of two major intestinal chemokines, TECK/CCL25 and MEC/CCL28, and their receptors. PLoS One (2007) 2(7):e677. doi:10.1371/journal.pone.0000677

151. Prescott SL. Early-life environmental determinants of allergic diseases and the wider pandemic of inflammatory noncommunicable diseases. J Allergy Clin Immunol (2013) 131(1):23-30. doi:10.1016/j.jaci.2012.11.019

152. Spor A, Koren O, Ley R. Unravelling the effects of the environment and host genotype on the gut microbiome. Nat Rev Microbiol (2011) 9(4):279-90. doi: $10.1038 /$ nrmicro 2540

153. Ifrim DC, Quintin J, Joosten LAB, Jacobs C, Jansen T, Jacobs L, et al. Trained immunity or tolerance: opposing functional programs induced in human monocytes after engagement of various pattern recognition receptors. Clin Vaccine Immunol (2014) 21(4):534-45. doi:10.1128/CVI.00688-13

154. Levy O, Netea MG. Innate immune memory: implications for development of pediatric immunomodulatory agents and adjuvanted vaccines. Pediatr Res (2014) 75(1-2):184-8. doi:10.1038/pr.2013.214

155. Burl S, Townend J, Njie-Jobe J, Cox M, Adetifa UJ, Touray E, et al. Agedependent maturation of toll-like receptor-mediated cytokine responses in Gambian infants. PLoS One (2011) 6(4):e18185. doi:10.1371/journal.pone. 0018185

156. Lisciandro JG, Prescott SL, Nadal-Sims MG, Devitt CJ, Pomat W, Siba PM, et al. Ontogeny of toll-like and NOD-like receptor-mediated innate immune responses in Papua New Guinean infants. PLoS One (2012) 7(5):e36793. doi:10.1371/journal.pone.0036793

157. Smolen KK, Ruck CE, Fortuno ES, Ho K, Dimitriu P, Mohn WW, et al. Pattern recognition receptor-mediated cytokine response in infants across 4 continents. J Allergy Clin Immunol (2014) 133(3):818.e-26.e. doi:10.1016/j.jaci. 2013.09.038

158. Brewer TF. Preventing tuberculosis with bacillus Calmette-Guerin vaccine: a meta-analysis of the literature. Clin Infect Dis (2000) 31(Suppl 3):S64-7. doi: $10.1086 / 314072$

159. Fine PE. Variation in protection by BCG: implications of and for heterologous immunity. Lancet (1995) 346(8986):1339-45. doi:10.1016/S0140-6736(95) 92348-9

160. Mangtani P, Abubakar I, Ariti C, Beynon R, Pimpin L, Fine PEM, et al. Protection by BCG vaccine against tuberculosis: a systematic review of randomized controlled trials. Clin Infect Dis (2014) 58(4):470-80. doi:10.1093/cid/cit790

161. Kernodle DS. Decrease in the effectiveness of bacille Calmette-Guérin vaccine against pulmonary tuberculosis: a consequence of increased immune suppression by microbial antioxidants, not overattenuation. Clin Infect Dis (2010) 51(2):177-84. doi:10.1086/653533

162. Black GF, Dockrell HM, Crampin AC, Floyd S, Weir RE, Bliss L, et al. Patterns and implications of naturally acquired immune responses to environmental and tuberculous mycobacterial antigens in Northern Malawi. J Infect Dis (2001) 184(3):322-9. doi:10.1086/322042

163. Lalor MK, Floyd S, Gorak-Stolinska P, Ben-Smith A, Weir RE, Smith SG, et al. BCG vaccination induces different cytokine profiles following infant BCG vaccination in the UK and Malawi. J Infect Dis (2011) 204(7):1075-85. doi:10.1093/infdis/jir515

164. Ritz N, Hanekom WA, Robins-Browne R, Britton WJ, Curtis N. Influence of BCG vaccine strain on the immune response and protection against tuberculosis. FEMS Microbiol Rev (2008) 32(5):821-41. doi:10.1111/j.1574-6976.2008. 00118.x

165. Wu B, Huang C, Garcia L, de Leon AP, Osornio JS, Bobadilla-del Valle M, et al. Unique gene expression profiles in infants vaccinated with different strains of Mycobacterium bovis bacille Calmette-Guerin. Infect Immun (2007) 75(7):3658-64. doi:10.1128/IAI.00244-07 
MacGillivray and Kollmann

Environmental factors modulating immune responses

166. Biering-Sørensen S, Aby P, Napirna BM, Roth A, Ravn H, Rodrigues A, et al. Small randomized trial among low-birth-weight children receiving bacillus Calmette-Guérin vaccination at first health center contact. Pediatr Infect Dis J (2012) 31(3):306-8. doi:10.1097/INF.0b013e3182458289

167. Ritz N, Muir M, Balloch A, Curtis N. Nonspecific effect of bacille CalmetteGuérin vaccine on the immune response to routine immunisations. Vaccine (2013) 31(30):3098-103. doi:10.1016/j.vaccine.2013.03.059

168. Shan F. Nonspecific effects of vaccines and the reduction of mortality in children. Chin Then (2013) 35(2):109-14. doi:10.1016/j.clinthera.2013.01.007

169. Gaayeb L, Pinçon C, Games C, Sur JB, Seck M, Schacht AM, et al. Immune response to Bordetella pertussis is associated with season and undernutrition in Senegalese children. Vaccine (2014) 32(27):3431-7. doi:10.1016/j.vaccine. 2014.03.086

170. Rise IM, Aby P, Whittle H, Jensen H, Engelmann M, Christensen LB. Tlymphocyte subsets in West African children: impact of age, sex, and season. J Pediatr (1997) 130(1):77-85. doi:10.1016/S0022-3476(97)70313-5

171. Collinson AC, Nom PT, Moore SE, Morgan G, Prentice AM. Birth season and environmental influences on blood leucocyte and lymphocyte subpopulations in rural Gambian infants. BMC Immunol (2008) 9(1):18. doi:10.1186/14712172-9-18

172. Moore SE, Cole TJ, Collinson AC, Poskitt EM, McGregor IA, Prentice AM. Prenatal or early postnatal events predict infectious deaths in young adulthood in rural Africa. Int J Epidemiol (1999) 28(6):1088-95. doi:10.1093/ije/28.6.1088

173. Moore SE, Collinson AC, Prentice AM. Immune function in rural Gambian children is not related to season of birth, birth size, or maternal supplementation status. Am J Chin Nutr (2001) 74(6):840-7.

174. Disanto G, Chaplin G, Morahan J, Giovannoni G, Hyppönen E, Ebers G, et al. Month of birth, vitamin D and risk of immune-mediated disease: a case control study. BMC Med (2012) 10(1):69. doi:10.1186/1741-7015-10-69
175. Martineau AR, Nhamoyebonde S, Oni T, Rangaka MX, Marais S, Bangani $\mathrm{N}$, et al. Reciprocal seasonal variation in vitamin $\mathrm{d}$ status and tuberculosis notifications in Cape Town, South Africa. Proc Natl Acad Sci US A (2011) 108(47):19013-7. doi:10.1073/pnas.1111825108

176. Panigrahi P, Parida S, Pradhan L, Vanda N, Satpathy R, Chandel D, et al. Effectiveness of a Lactobacillus plantarum symbiotic therapy for preventing late onset sepsis in neonates [abstract]. Pediatric Academic Societies Annual Meeting. Washington, DC (2013).

177. de Wit R, Bouvier T. 'Everything is everywhere, but, the environment selects'; what did Baas Backing and Beijerinck really say? Environ Microbiol (2006) 8(4):755-8. doi:10.1111/j.1462-2920.2006.01017.x

Conflict of Interest Statement: The authors declare that the research was conducted in the absence of any commercial or financial relationships that could be construed as a potential conflict of interest.

Received: 16 July 2014; accepted: 26 August 2014; published online: 12 September 2014. Citation: MacGillivray DM and Kollmann TR (2014) The role of environmental factors in modulating immune responses in early life. Front. Immunol. 5:434. do: 10.3389/fimmu.2014.00434

This article was submitted to Immunotherapies and Vaccines, a section of the journal Frontiers in Immunology.

Copyright (C) 2014 MacGillivray and Kollmann. This is an open-access article distribute under the terms of the Creative Commons Attribution License (CC BY). The use, distribution or reproduction in other forums is permitted, provided the original author (s) or licenser are credited and that the original publication in this journal is cited, in accordance with accepted academic practice. No use, distribution or reproduction is permitted which does not comply with these terms.

Frontiers in Immunology | Immunotherapies and Vaccines

September 2014 | Volume 5 | Article 434 | 12 